\title{
BEBÉS ROBADOS: DE LA CRUDA REALIDAD A LA FICCIÓN
}

\author{
Dácil Vera González \\ Delegada en Canarias de SOS Bebés Robados Madrid
}

\section{RESUMEN}

En España ha sido un secreto a voces que se compraban y vendían bebés. Se trata de una trama bien establecida, que podría ubicarse en el tiempo entre el final de la guerra civil española y bien avanzada la década de 1990. Se ha estimado la cifra de 300000 robos. Muchas de estas personas no supieron nunca que sus padres no eran sus padres biológicos, y muchas aún no lo saben. Una gran cantidad de mujeres fueron castigadas por la sociedad, al ser madres solteras, y otras simplemente creyeron lo que les dijo el médico o la monja, «se murió, venía mal y es mejor que no lo veas». Otras se desviven por encontrar a sus familiares, madres e hijos, en un país donde todavía resulta ser un tema tabú en todos los estamentos. No solo España ha pecado de la venta de bebés, es un crimen que recorre todo el planeta. Irlanda, donde la Iglesia católica gestionó miles de ventas disfrazándolas de adopciones. Serbia, sumida en la miseria y bajo un manto de absoluto silencio. Argentina, bajo una dictadura que humilló a la mujer robándole a sus hijos para dárselos a sus maltratadores. El medio audiovisual se ha hecho eco de este crimen, a través del cine, la televisión y el documental, convirtiéndose no solo en entretenimiento, sino en una forma de comunicar. Son muchos los casos en que un espectador se ha empezado a hacer preguntas sobre su propia historia. Ha dado a conocer la historia, para que nunca vuelva a repetirse.

Palabras clave: bebés robados, venta de bebés, guerra civil española, crimen.

\section{STOLEN BABIES: FROM CRUEL REALITY TO THE BIG SCREEN}

\section{Abstract}

In Spain is an open secret, that were bought an sold babies. It's a well established plot, located in time between endings of Spanish Civil War and late 1990s. 300000 substractions has been estimated. Many of these people never knew that their parents were not their biological parents, and many still do not know. A lot of women was punished by society for being single mothers, and others simply belived what the doctor or nun told them, «they died, they came wrong, is better you don't see them». Others go out of their way to find their relatives, mothers and children, in a country where it still turns out to be a taboo subject in all staments. Not only Spain sins of the sale of babies, it is a crime that goes all over the planet. Ireland, where the Catholic Church managed thousands of sales disguising them as adoptions. Serbia, plunged into misery and under a blanket of absolute silence. Argentina, under a dictatorship that humiliated women by stealin from their children to give to their abusers. Media have echoed this crime, through cinema, televisión and documentary, becoming not only entertainment, but also a way of communicating. There are many cases in which a viewer has begun to ask questions about their own stories. It has made history known, so that it never repeats itself.

Keywords: Stolen babies, baby sale, Spanish Civil War, crime.

DOI: https://doi.org/10.25145/j.latente.2020.18.09

Revista Latente, 18; noviembre 2020, pp. 227-236; ISSN: e-2386-8503 


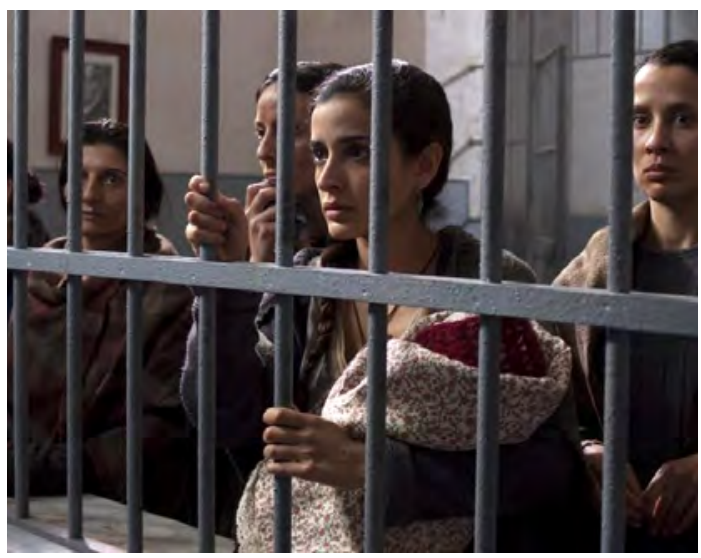

La voz dormida.

En el tema que nos ocupa, los bebés robados, el cine se ha preocupado de transmitir sórdidas realidades, convirtiéndose así en un mecanismo de comunicación. Para ello ha llevado esta cuestión a los espectadores en diferentes formas, siendo en España las más habituales la miniserie, generalmente en dos capítulos, y el documental, que se convertirían en laureados largometrajes. Estas producciones giran en torno a varios problemas: el robo en sí y quienes lo practicaban (en España han sido punta de lanza el ginecólogo Eduardo Vela y sor María Valbuena), la crisis de identidad que genera en los «adoptados»" saber que su origen es diferente al que creían y que puede que nunca sepan la verdad, y el de madres y padres que claman justicia por haber sido engañados con un fin económico.

\section{ESPAÑA, BAJO EL YUGO Y LA FLECHA}

En materia de bebés robados, en España podríamos poner como punto de partida del estudio, el establecimiento de la dictadura franquista y las dos primeras décadas de la democracia (1938-1996)².

Este recorrido histórico comienza, cinematográficamente hablando, con $\mathrm{La}$ voz dormida, dirigida por Benito Zambrano en 2011. La historia arranca en 1940, en la cárcel de Ventas, Madrid. En medio de una húmeda oscuridad, unas monjas citan

1 «Adoptados» irá en este artículo casi siempre entrecomillado, por hacer referencia a adopciones ilegales o a falsos biológicos. Esto es, bebés que fueron inscritos como hijos biológicos cuando no lo eran, creando una falsa identidad legal y eliminando el rastro de su identidad biológica.

2 Roig Pruñonosa, N. (2018): No llores que vas a ser feliz. El tráfico de bebés en España: de la represión al negocio (1938-1996), Barcelona, Ático de los libros, p. 26. 
los nombres de las mujeres que van a ir al paredón esa noche. Hortensia está presa por ser republicana y gran parte de la trama gira en torno a qué va a ocurrir con su bebé. De ese bebé, dicen en la cárcel aún puede ser recuperado para la nueva causa.

Esta nueva causa se refiere a la dictadura franquista y entre sus filas contaba con la presencia de Antonio Vallejo-Nágera, psiquiatra y militar, que sostenía teorías eugénicas de herencia nazi, en las que habla de la necesidad de eliminar cualquier vestigio genético marxista (a los que califica de plaga) para mantener la pureza de la raza hispana.

Vallejo-Nágera no se limitó al terreno teórico [...] su influjo con teorías seudocientíficas afectaron a las relaciones que tuvieron muchas de las presas republicanas con sus hijos, en algunos casos muertos por inanición o separados de sus madres sin saber jamás cual sería su paradero ${ }^{3}$.

Evidentemente, en su escala de valor social, sitúa a la mujer en el más bajo escalafón, cuya única utilidad es la de procrear. Pero buscando la forma de no transmitir ideas contrarias al régimen, una de las formas de llevarlo a cabo era la de dar los bebés nacidos de madres republicanas a familias afines a este.

Parécenos que mucho más que las condiciones antropológicas de los progenitores influyen en la descendencia, por razones que ampliamente expondremos, las ideas morales y culturales del pueblo ${ }^{4}$.

En torno a esta idea gira gran parte de la película. Cuando Hortensia da a luz en la cárcel, su miedo crece, no solo a ser fusilada, sino a que su hija crezca sin conocer su origen.

En este recorrido histórico, no puede faltar el documental El silencio de otros $^{5}$. Así, en silencio, se queda el espectador después de sus 95 minutos de duración. La dirección de Almudena Carracedo y Robert Bahar narra la lucha en silencio de víctimas de la dictadura franquista debido a que la Ley de Amnistía de 1977 ha permitido vivir impunes a los culpables. Con la producción ejecutiva de El Deseo, han recibido premios alrededor de todo el mundo, desde un Goya hasta un Óscar.

Entre todos los crímenes, cuentan el de las madres a las que les robaron sus bebés a través del testimonio de M. ${ }^{a}$ de las Mercedes Bueno, presidenta de ALUMBRA (Asociación de Lucha de las Madres de Bebés Robados en Andalucía), cuyo delito fue ser madre soltera en 1977, y cayó un 24 de diciembre en manos de un ginecólogo que le dijo que era mejor dormirla para el parto, y posteriormente que

\footnotetext{
${ }^{3}$ https://memoriahistorica.org.es.

4 Vallejo-Nágera, A. (1937): Eugenesia de la hispanidad y regeneración de la raza, Burgos, p. 77.

5 Carracedo, A. y Bahar, R. (dirección) (2018): El silencio de otros [documental], España, Semilla Verde Production, Lucerna Films, American Documentary POV, Independent Television Service, Latino Public Broadcasting (LPB), El Deseo.
} 


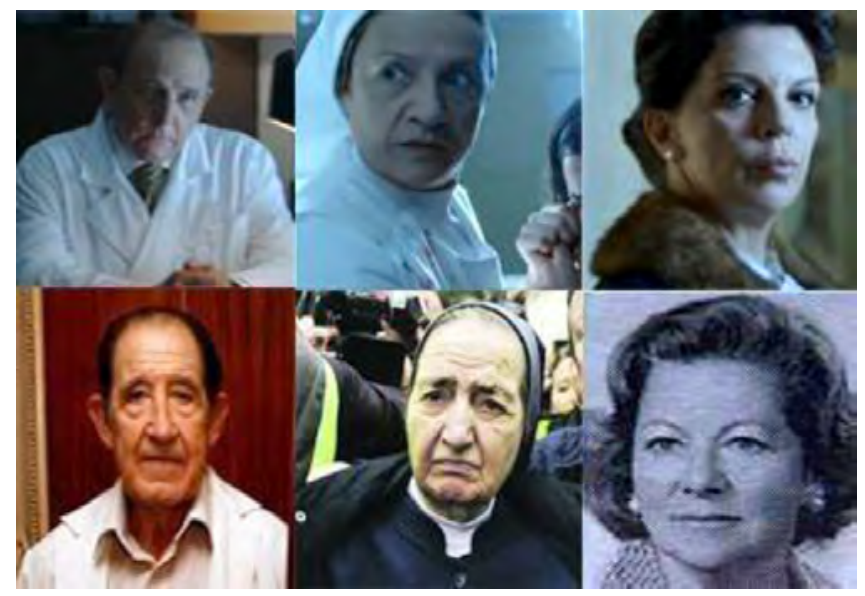

Personajes en la ficción y en la realidad. De izq. a der. Dr. Mena (Dr. Vela), sor Eulalia (sor María), Dolores de Prat (Mercedes de Gras).

el bebé había muerto. Veintiocho años después, por la avalancha de denuncias en medios de comunicación, supo que la habían engañado.

Pero no, no podemos culpar solo al franquismo del delito de robo de bebés. Ya sea en la Transición hacia la Democracia, o en plena Democracia, se han seguido robando recién nacidos en España. Asociaciones españolas de ayuda a las víctimas poseen datos de esta práctica hasta en 2001.

Es a comienzos de la década de 1980 cuando la periodista Margarita Antonia Iglesias recibe en la redacción de Interviú la llamada de unas enfermeras desde la clínica San Ramón de Madrid, diciendo que ahí había un bebé congelado que enseñaban a las madres, pero sus recién nacidos ya se habían marchado con unos nuevos padres, adjudicados por el doctor Eduardo Vela Vela, el «hacedor de nińos». La foto que realizó Germán Gallego, de un bebé congelado y amoratado, no puede dejar a nadie indiferente.

No trabajaba solo, sino con la ayuda de sor María Valbuena, trabajadora social de la clínica Santa Cristina de Madrid, y de Mercedes Herrán de Gras, amiga de Francisco Franco y dueña de "pisos patera» en Bilbao, donde mantenía ocultas a madres solteras hasta que daban a luz.

Reflejada, contada e investigada a fondo queda esta trama para la miniserie Niños robados ${ }^{6}$. Su novedad en cuanto a otras es que trata el problema desde dos puntos de vista: las madres que dieron a luz y aquellos bebés robados, hoy hombres y mujeres, con todo el dolor que acarrean.

6 Telecinco (2013): Niños robados [serie de televisión], España, Mod Producciones. 
La primera parte, a su vez, proporciona dos tipologías de madre biológica diferentes: la que se cree que su niña murió (Violeta) y la que sabe a ciencia cierta que le robaron a la suya (Conchita).

La segunda parte cuenta lo que significa para Susana, una chica de alta sociedad, descubrir que la han engañado, y que sus padres no son sus padres ${ }^{7}$. Es el comienzo de la búsqueda de su identidad, con la ayuda de abogados, asociaciones de víctimas, amigos, familia, etc.

\section{IRLANDA, EN EL NOMBRE DE DIOS}

En Irlanda, a diferencia de España, lo que se hacía era forzar las adopciones, casi en su totalidad ilegales. Se habla de «adopciones» que en 1952 costaron mil libras. Aquí estaba involucrada de pleno la Iglesia católica con la connivencia del Gobierno, que toleraba y facilitaba esta práctica "por el bienestar de los niños» ${ }^{8}$.

Esta historia la hace suya el cine en forma de drama en dos largometrajes: Las hermanas de la Magdalena y Filomena ${ }^{10}$, ambas basadas en hechos reales. Aunque tratan de las prácticas de un mismo lugar, la primera se centra en la vida que llevaban las madres solteras y los trabajos forzados a los que eran sometidas durante su estancia en las casas de la congregación del Sagrado Corazón de Jesús (Bessborough, Castlepollard, Sean Ross Abbey y Tuam) ${ }^{11}$.

La película Las hermanas de la Magdalena no ahorra dolor al espectador. La sensación de encierro se acentúa con una iluminación en clave baja. Mujeres jóvenes cuyo pecado era ser jóvenes simplemente, o haber sido violadas y haber engendrado un hijo. Se sesga su identidad, ya no pueden usar su nombre sino el que les sea asignado por las monjas. Cualquier comportamiento considerado indecente acaba con un rapado de cabeza que elimina de un golpe, o a golpes, la femineidad de estas jóvenes.

El pecado se lavaba con agua hirviendo en la que se escaldaban las manos. Eran algunas de las 30000 mujeres que fueron forzadas a trabajar en las lavanderías

7 No cabe valorar la infidelidad a los sentimientos por los padres «adoptivos». Existen muchos «adoptados» que no quieren buscar a su familia biológica por sentirse infieles a sus padres «adoptivos», y otros que no quieren volver a saber de ellos cuando saben la verdad. Es tan respetable una posición como la otra.

8 Trenado, M. (2015): «The cases of 'Stolen children' in Spain and Ireland, Curtailing the mos suitable legal framework on the fight for 'real' identities», ICL Journal, p. 21, Viena.

9 Mullan, P. (director). (2002): The Magdalena sisters, [drama/religión, basado en hechos reales], coproducción Irlanda-Reino Unido, PFP Films, Temple Films.

${ }^{10}$ Fears, S. (director). (2013): Philomena [drama basado en el libro de Martin Sixsmith], coproducción Reino Unido-Estados Unidos-Francia, BBC Films, Pathé, Baby Cow Prod., British Film I. Magnolia Mae Films.

${ }^{11}$ Donde se encontraron en 2014 ochocientos esqueletos de recién nacidos en una fosa séptica gracias a la historiadora Catherine Corless. Posteriormente se encontraron más, y se les dio el nombre de «parcelas de ángeles». 


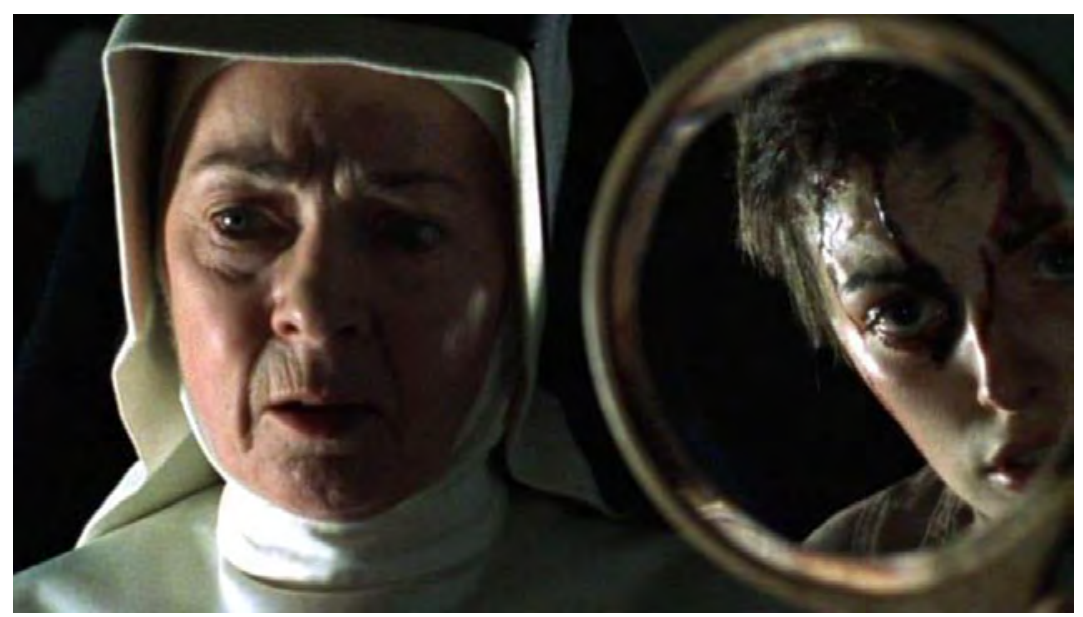

Las hermanas de la Magdalena.

de los asilos de la Magdalena. Es llamativo el paralelismo que existe con el Patronato para la protección de la mujer, con D. ${ }^{a}$ Carmen Polo de Franco como fundadora, donde las mujeres eran obligadas a coser ropa para grandes empresas. La última de estas lavanderías irlandesas fue cerrada en 1996.

Filomena narra el camino que tuvo que seguir Annie Philomena Lee, nacida en Limerick, Irlanda, en 1933, quien al quedarse embarazada a los 18 años fue a parar a Sean Ross Abbey en Roscrea, un centro para madres solteras. Allí nació Anthony Lee, posteriormente Michael Anthony Hess en Estados Unidos. Para poder salir de allí, debían trabajar, evidentemente sin salario, durante cuatro años, o bien pagar cien libras.

La película se centra en la búsqueda de Anthony por Philomena, con la ayuda de Martin, un periodista cuyo cometido es escribir un artículo «de interés social». "Llevo lo que me ocurrió dentro 50 años», dice Philomena, igual que tantos miles de madres a las que les robaron sus hijos, o se vieron obligadas a darlos mediante coacción.

Curiosamente, cuando retorna a la abadía para pedir los documentos de su hijo, las monjas le responden que todo había desaparecido en un incendio, pero lo que sí conservan es la renuncia que ella firmó 50 años atrás.

Animada por el periodista, viaja a Estados Unidos siguiendo una pista, para descubrir que Anthony también emprendió un viaje en busca de su identidad. La película nos muestra una Philomena miedosa que no responde a la realidad, pues movería cielo y tierra para encontrar a su hijo, llegando a hacer confesar a las monjas lo que habían hecho con él y dejando claro que nunca quiso darlo en adopción. 


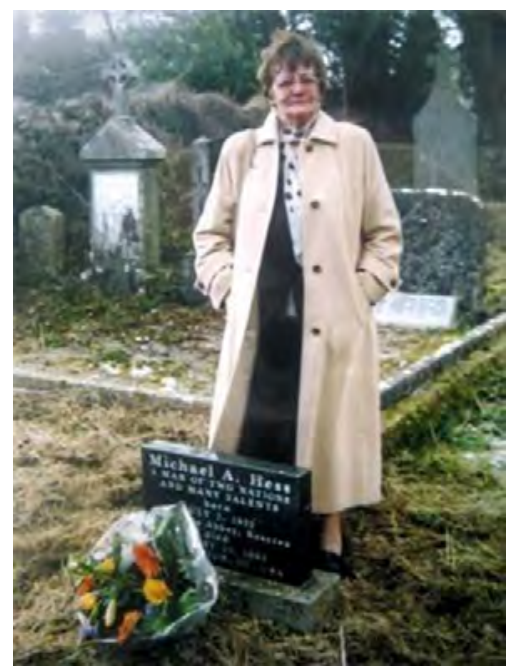

Philomena Lee delante de la tumba de su hijo en Irlanda.

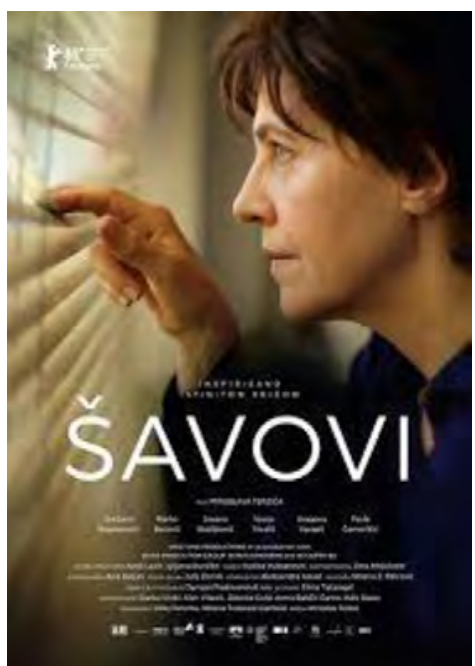

Cartel de la película Šavovi (Stitches).

\section{SERBIA, SIMPLEMENTE LA VERDAD}

El robo de bebés en Serbia es un gran conocido y a la vez desconocido. No sorprende que un país que ha sufrido guerras de todo tipo tenga una ciudadanía que vive bajo la ley del silencio. A pesar de las tres mil denuncias existentes, se estima que diez mil bebés han sido robados en los últimos cuarenta años, con un coste en los últimos tiempos de entre 15000 y $45000 €$ por niño.

En palabras de Mirjana Novokmet, madre de un bebé robado, la esperanza de saber la verdad no puede comprarse. Las pronuncia al saber que el Gobierno de su país ofrecerá mediante ley diez mil euros a cada familia que no haya encontrado documentación en relación con la búsqueda de su bebé.

Šavovi $i^{12}$ narra la búsqueda que Ana y su marido Jovan iniciaron cuando les dijeron que su hijo había muerto y que era mejor que no viesen el cadáver porque estaba lisiado y había sido lo mejor que le podía pasar. Representan al joven matrimonio que es fácilmente engañado. Su propio entorno le pide a Ana que olvide la búsqueda, pues el niño debe haber cumplido ya 18 años y tendrá una vida con otra familia. Ana solo quiere saber la verdad y, junto a Jovan, poner en orden todos los elementos de su vida. Encontrar a Markus va a poner punto y final en el dolor.

12 Tataragic, E. (productor) y Miroslav, T. (director) (2019): Šavovi (Stitches), Serbia, Eslovenia, Croacia, Bosnia, Herzegovina. 


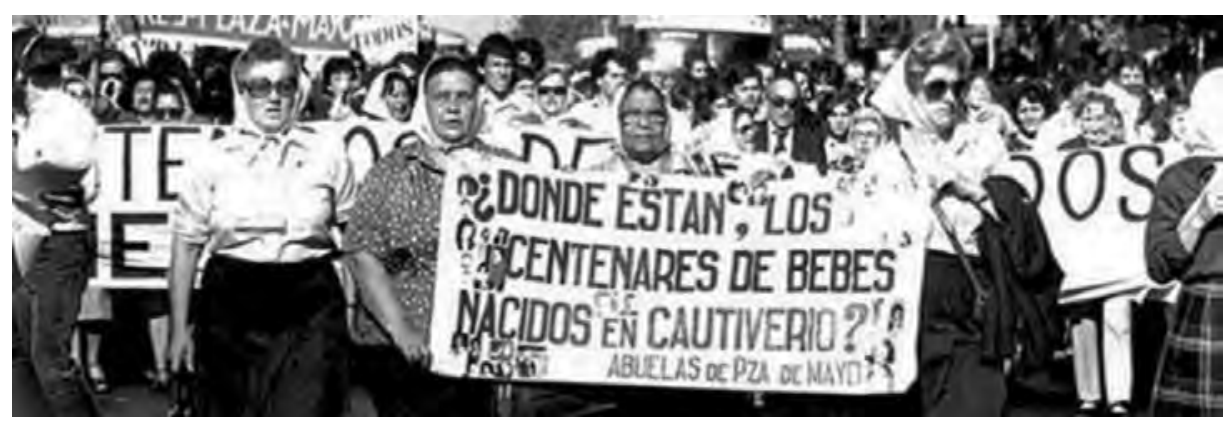

Las Madres de Plaza de Mayo manifestándose.

\section{ARGENTINA, NI MUERTO NI VIVO, DESAPARECIDO}

Todos son mis hijos ${ }^{13}$ es el documental que recoge la historia de las madres y abuelas de plaza de Mayo.

El 24 de marzo de 1976 Argentina se sume en el terror impuesto por las Fuerzas Armadas. Treinta mil desaparecidos, un genocidio, crimen de lesa humanidad. Sin embargo, los criminales, policías de gatillo fácil, quedan impunes. Muchas de las mujeres capturadas por los militares estaban embarazadas en ese momento, otras quedaron en estado en las prisiones debido a los abusos que sufrieron. Todas tuvieron en común que ninguna conservó a sus hijos, y ni siquiera sus vidas.

La Asociación Madres de Plaza de Mayo produce este desgarrador documental con la dirección de Ricardo Soto Uribe y fotografía de Facundo Geli. El comienzo se sitúa en Buenos Aires en 2001, donde los tanques militares invaden la ciudad entre disparos y lamentos por los muertos. Nada ha cambiado.

Cada testimonio duele más que el otro. Abuelas cuentan la historia de cómo iban día tras día a preguntar por sus desaparecidos, y la respuesta siempre era «no figura, vuelva dentro de cuarenta días». Ante la impotencia, madres con las manos vacías y los corazones rotos, empezaron a reunirse en plaza de Mayo para pedir silenciosamente que les devolvieran a sus hijos y nietos. Hicieron del pañuelo blanco en la cabeza su símbolo, como representación de los pañales de sus hijos. El manejo del lenguaje cinematográfico en este documental hace que el espectador quiera consolar a estas abuelas que nos cuentan sus historias, llenas de muerte pero también de esperanza. En 1980, aún en plena dictadura, encontraron a las dos primeras nietas. A día de hoy, han encontrado a 130, de los que muchos convivieron sin saberlo con los asesinos de sus padres biológicos.

13 Ceballos, M. y Paul, A. (productores) y Soto Uribe, R. (director) (2016): Todos son mis hijos [documental], Argentina. 


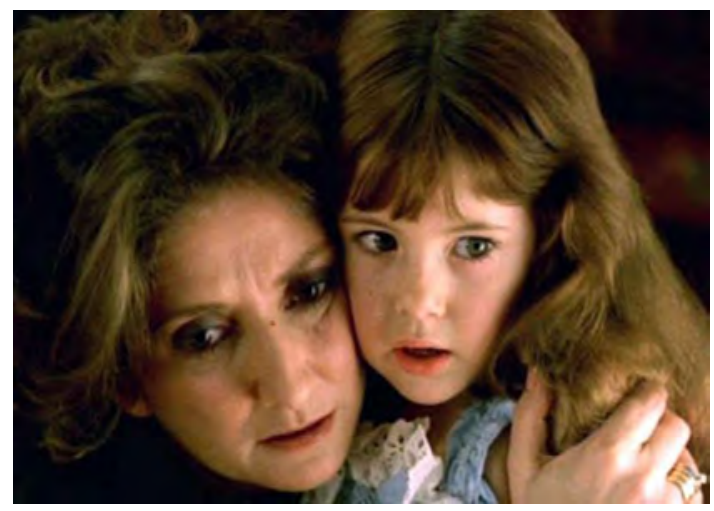

La historia oficial.

Curiosamente, en 1985 se estrenaría una película que ofrecía al espectador un punto de vista con el que hoy no solemos contar, las dudas sobre la procedencia de su hijo por parte de su madre adoptiva, y las consecuencias morales que le acarrea. La historia oficial ${ }^{14}$ muestra sin reparos las conversaciones entre un grupo de amigos acerca de cómo había estado el padre presente en el nacimiento de su hija Gabriela. Evidentemente, hablan de una represaliada militar y él no es el padre del bebé. Por otro lado, la «madre» se reencuentra con una vieja amiga, que había desaparecido sin dejar rastro, y esta le cuenta cómo fue vejada, violada y maltratada por amigos de su marido. Esto abre los ojos a la madre de Gabriela, y comienza a hacer preguntas incómodas sobre el origen de la niña a su esposo. Como dato común al de muchas víctimas de la sustracción de recién nacidos, festejan como cumpleaños de la niña el día que se la quedaron, no el que nació. Es otra forma más de robo de la identidad biológica.

El impacto del filme fue muy importante, siendo seleccionada para los Óscar y ganando por primera vez para un país de Latinoamérica la preciada estatuilla para la mejor cinta de habla no inglesa.

\section{ACABANDO, QUE NO FINALIZANDO}

No finalizando, porque el robo de bebés no ha puesto punto y final. Este crimen de lesa humanidad no finalizará hasta que los gobiernos no se comprometan en su totalidad a impartir justicia, a la reparación de los daños y a la no repetición.

14 Puenzo, L. (director) (1985): La historia oficial [drama, dictadura argentina], Argentina, Historias cinematográficas, Progress Communications. 
Esto solo se consigue mediante leyes sinceras y de debido cumplimiento, como la que se acaba de admitir a trámite -el 23 de junio de 2020- en España.

Dicen que lo último que se pierde es la esperanza, pero en España, solo una de las víctimas consiguió llevar al ginecólogo Eduardo Vela a juicio antes de su muerte: Inés Madrigal, con el letrado Guillermo Peña como abogado. La sentencia del Tribunal Supremo de España ha sido no pronunciarse sobre los aspectos que hubiesen permitido reabrir cientos de casos en el país y condenar a la víctima a pagar las costas del juicio.

¿Será que Democracia ahora se escribe con minúscula?

La realidad es que aún, de muy diversos países, llegan noticias de mujeres secuestradas hasta dar a luz para vender a sus bebés. Mientras exista quien quiera comprar, existirá quien robe para vender.

Recibido: abril de 2020; ACEptado: junio de 2020 